Agro-Science Journal of Tropical Agriculture, Food, Environment and Extension Volume 9 Number 1 January 2010 pp. $24-30$

ISSN 1119-7455

\title{
BLOCK PATTERN TECHNOLOGY: A MEANS OF REVAMPING THE CLOTHING INDUSTRY IN NIGERIA
}

\author{
Iloeje $^{1}$, C.I. and Anyakoha ${ }^{2}$, E.U. \\ ${ }^{1}$ Department of Home Science, Nutrition \& Dietetics, \\ University of Nigeria, Nsukka, Nigeria. \\ ${ }^{2}$ Department of Vocational Education, University of Nigeria, Nsukka, Nigeria.
}

\begin{abstract}
The main purpose of this study was to develop bodice block patterns for female youths in three size categories- small, medium and large as well as test the fit of the garments constructed from the blocks. The area of study was Enugu State. The study was carried out in two phases: development of bodice block patterns for the subjects in three sizes using body measurements already established from 900 female youths and evaluation of the fit of the garments developed from the blocks. Three models were used to test the fit of the garments constructed from the blocks. Purposive sampling was used to select 30 judges. The evaluation instrument for rating the fit of the garments constructed from the blocks was a five point rating scale. Data generated were analysed using Mean, ANOVA and the Duncan's New Multiple Range Test (DNMRT). Nine blocks comprising three back bodice blocks, three front bodice blocks and three sleeve blocks were developed for the three size categories. Bodices were constructed from the developed blocks to test for fit. The fit of the garments were rated very satisfactory by the three sets of judges on nearly all the variables tested.
\end{abstract}

Key words: Block, Pattern, Technology, Clothing Industry, Nigerian's economy.

\section{INTRODUCTION}

The clothing industry is also recognized as one of the major employers of labour. In the USA for instance, Jarrow and Dickerson (1996) observed that the apparel manufacturing industry employed more people than the entire publishing, printing field and the automobile manufacturing industries together. New York had an estimated 4,500 clothing factories employing about 225,000 workers in design, manufacturing and distribution (Frings, 1999). Unlike the textile industry that is capital intensive, the clothing industry depends much less on capital investment and more on the skill of the individual workers (Rose, 2000). The apparel manufacturing industry makes use of block for large scale production.

A block in apparel production refers to the shape and form in which a garment is presented. It is a plain pattern that is used as a basic from which style adaptations are made (Aldrich 2002). There are many types of blocks and they vary in details, methods of construction and presentation. They include the standard block, the simplified block, the trade block and the tailoring block, among others. The standard block was developed for this study. The standard block is the basic foundation which follows the natural lines of the figure and from it, more specialized blocks can be produced (Bray, 1994). Block patterns can be developed by drafting or draping or a combination of these methods (Hollen and Kundel, 1993). Drafting is a method of obtaining patterns by using a set of prescribed measurements and following a set of instructions in order to obtain each piece. Draping on the other hand involves working directly with a fabric on a model or dress form to obtain a cloth pattern. It is also referred to as modeling.

Studies have shown that Nigeria does not have blocks for her populace which are basic to large scale production of garments (Kaka, 1990; Iloeje and Anyakoha, 2003). Dressmakers in Nigeria usually engage in custom made sewing which is the making of garments from start to finish for specific individuals. It is obviously difficult to satisfy 
the huge demand for clothing by this small scale method of production.

In Nigeria, there is presently massive importation/smuggling of garments and other textile goods. This is in spite of the various government policies and programmes that are designed to stop importation and promote local production. This has led to serious consequences including job losses. Report from National Union of Textile, Garment and Tailoring Workers of Nigeria (NUTGTWN, 2004) indicated that 50 textile firms across the country had been shut down between 1995 and 2000. They also noted that 174 textile industries that were functional before 1994 had been reduced to 40 with about 30,000 job losses. As of 2004, agricultural and nonagricultural goods, including textiles and clothing, were subjected to import restrictions mainly for purposes of protecting the domestic industries (Oyejide et al., 2005). They also observed that import prohibition had been rendered virtually impotent by large scale smuggling, in spite of the stiff penalties imposed on those involved in the importation, transportation, storage, display and sale of prohibited items. Import actually represents the gap between what the country needs and what it is able to produce. For Nigeria to depend heavily on imported goods, it means she is providing jobs for persons in countries other than her own. This situation is quite worrisome. This is a challenge.

The Federal Government of Nigeria has over the years adopted a number of measures towards revamping the Nigerian economy. One of such measures is the Structural Adjustment Programme (SAP) of 1986, the main objective of which was economic self reliance. Also, in 2002, the Federal Government of Nigeria adopted a medium term economic package - The National Economic Empowerment and Development Strategy (NEEDS) for the period 2003-2007. The main focus of NEEDS included (i) re-orienting values, (ii) reducing poverty, (iii) creating wealth and (iv) generating employment (FGN, 2004). With the availability of blocks for female youths, large scale production of garments for the target group can flourish. This will lead to reduction in importation of garments and creation of more jobs, thereby conserving Nigeria's foreign reserves, reducing unemployment and increasing wealth.

\section{Purpose of the Study}

The main purpose of the study was to develop bodice and sleeve blocks for Nigerian female youths (15-24 years of age). Specifically, the study

(i) drafted three sets of bodice and sleeve blocks for female youths 15 to 24 years of age for small, medium and large size categories.

(ii) constructed three bodices for each size from the blocks developed.

(iii) determined the fit of garments, developed from the blocks, using models representing the three size categories (first modeling).

(iv) constructed another set of three bodices for the three sizes using the modified/corrected blocks.

(v) evaluated the fit of the bodices developed from the modified blocks (final modeling).

\section{Hypotheses}

Three null hypotheses were tested in this study at 0.05 level of significance, in respect of the judges` ratings, viz:

$\mathrm{Ho}_{1}$ : There is no significant difference in the mean rating of the three sets of judges (lecturers, students and seamstresses) on the fit of the bodice for small size.

$\mathrm{Ho}_{2}$ : There is no significant difference in the mean rating of the three sets of judges on the fit of the bodice for medium size.

$\mathrm{Ho}_{3}$ : There is no significant difference in the mean rating of the three sets of judges on the fit of the bodice for large size.

\section{MATERIALS AND METHODS}

The area of study was Enugu State. The Research and Development (R\&D) design was employed in carrying out this study. The study was carried out in two phases. The first phase developed the bodice block patterns for the subjects in three sizes using body measurements already established using 900 females (Iloeje 2007). The second phase involved (i) constructing garments from the blocks,(ii) testing the fit of the garments using three models representing small, medium and large sizes (iii) modification of the blocks, (iv) repeat of steps i - iii until satisfactory fits are obtained.

Thirty judges (males and females) comprising 10 Home Economics lecturers, 10 Home Economics students and 10 garment producers were used for the assessment of fit. These judges were purposively drawn from the University Community and the Nsukka Urban town. The criteria for selecting the lecturers and seamstresses were a minimum of five years teaching or sewing experience as applicable. The students selected were in their final years and had taken courses in pattern 
drafting and clothing construction. The judges were given training prior to the scoring of the evaluation instrument. Models, one for each size were also selected following standard criteria. The rating instrument for the study was a five point rating scale for scoring the fit of the garments constructed from the developed block patterns. A mean rating of $2.60-3.35$ was regarded as acceptable range for good fit.

The reliability of the instrument was established using Kendal for inter-rater reliability. This was because the items (variables) were being rated by more than one person and inter-rater-reliability is appropriate for estimating the relationship between the scores of raters. The coefficient obtained for each cluster is as follows:

$\begin{array}{llll} & \text { Small } & \text { Medium } & \text { Large } \\ \text { Lecturer } & .72 & .75 & .87 \\ \text { Student } & .82 & .81 & .82 \\ \text { Seamstresses } & .77 & .84 & .78\end{array}$

The data generated by the hypotheses of the study were analysed using the Mean, One-Way Analysis of Variance (ANOVA) and the Duncan's New Multiple Range Test (DNMRT).

\section{RESULTS}

A set of nine blocks comprising bodice front, bodice back and sleeve was developed for the small medium and large size categories. A sample is presented in Figures 1-IV. The mean f-ratio and DNMRT results of ratings by judges on the fit of bodices (small, medium and large) are presented in Tables 1-3 below.

The lecturers rated all the 14 variables used in assessing the fit of the bodice for small size good fit which is within $2.60-3.35$. The mean ratings of the seamstresses in all the 14 variables also fell within the good fit range. The students also recorded good fit in 13 out of the 14 variables for assessing the fit of the bodice for small size. The variable that recorded poor fit was (item 10) 'armscye' depth with a mean score of 2.50

For hypothesis testing, $\mathrm{H}_{\mathrm{ol}}$, Table 1 shows that there were no significant differences in the mean ratings of the judges on 13 out of 14 variables (about 93 percent) used in assessing the fit of the bodice for small size. Significant difference occurred in only one variable (item 14) 'armhole seam'. The null hypothesis of no significant difference was rejected for (item 14) 'armhole seam' and accepted for the remaining 13 variables that were used in scoring the fit of the bodice for small size.

Table 1: Mean F-ratio and DNMRT Results of the Judges on the Fit of the Bodice for Small Size

\begin{tabular}{|c|c|c|c|c|c|c|c|}
\hline $\mathrm{S} / \mathrm{N}$ & Variables & $\bar{X}_{1}$ & $X_{2}$ & $\bar{X}_{3}$ & $\bar{X}_{4}$ & F-Cal & Sig. \\
\hline 1 & Neckline & 3.00 & 3.00 & 2.90 & 2.97 & 1.00 & .381 \\
\hline 2 & Shoulder seam length & 3.00 & 3.00 & 3.00 & 3.00 & - & - \\
\hline 3 & Bust ease & 3.00 & 2.90 & 2.70 & 2.87 & 2.10 & .142 \\
\hline 4 & Upper back & 3.00 & 2.80 & 3.00 & 2.93 & 1.13 & .339 \\
\hline 5 & Waistline & 3.00 & 3.00 & 3.00 & 3.00 & - & - \\
\hline 6 & Waistline placement (front) & 3.00 & 3.00 & 3.00 & 3.00 & - & - \\
\hline 7 & Waistline placement (back) & 3.00 & 3.00 & 3.00 & 3.00 & - & - \\
\hline 8 & Front bodice waistline dart length & 3.00 & 3.00 & 3.20 & 3.06 & 2.250 & .125 \\
\hline 9 & Back bodice waistline dart length & 3.30 & 3.30 & 3.00 & 3.20 & 1.929 & .165 \\
\hline 10 & Armscye depth & 2.90 & $2.50 * *$ & 2.80 & 2.73 & 2.340 & .116 \\
\hline 11 & Ease at biceps & 3.00 & 3.00 & 2.90 & 2.97 & .310 & .736 \\
\hline 12 & Sleeve cap ease & 3.00 & 3.00 & 2.80 & 2.93 & 2.250 & .125 \\
\hline 13 & Sleeve length & 3.00 & 2.70 & 2.70 & 2.80 & 1.929 & .165 \\
\hline 14 & Armhole seam & $3.00_{\mathrm{ab}}$ & $3.20_{\mathrm{a}}$ & $2.80_{\mathrm{b}}$ & 3.00 & 3.375 & $.049 *$ \\
\hline
\end{tabular}

$\bar{X}_{1}=$ mean ratings by lecturers, $\bar{X}_{2}=$ mean ratings by students, $\bar{X}_{3}=$ mean ratings

by seamstresses, $\bar{X}_{4}=$ grand mean, $*=$ significant, $\mathrm{P}=.05, * *=$ poor fit, a $=$ ab (no

significant difference), $\mathrm{b}=\mathrm{ab}$ (no significant difference), $\mathrm{a} \neq \mathrm{b}$ (significant difference) 
FIGURES

Figure 1: Drafted Bodice Blocks (Front and Back)

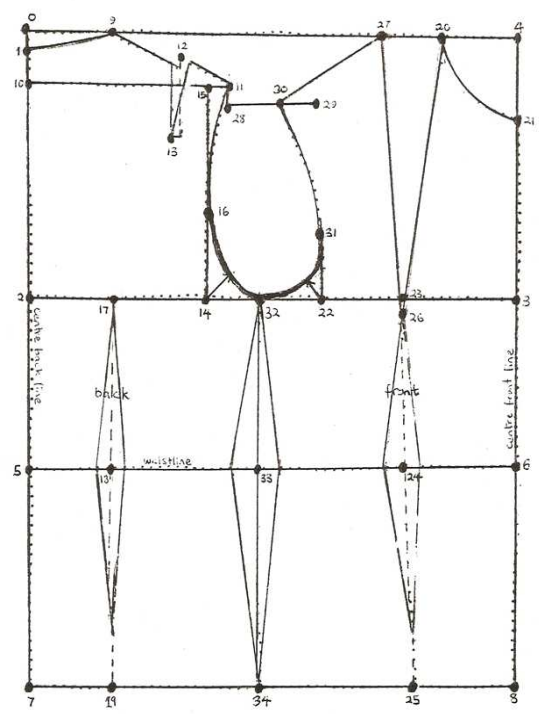

Fgure 3: Developed Bodice Blocks (Front and Back)

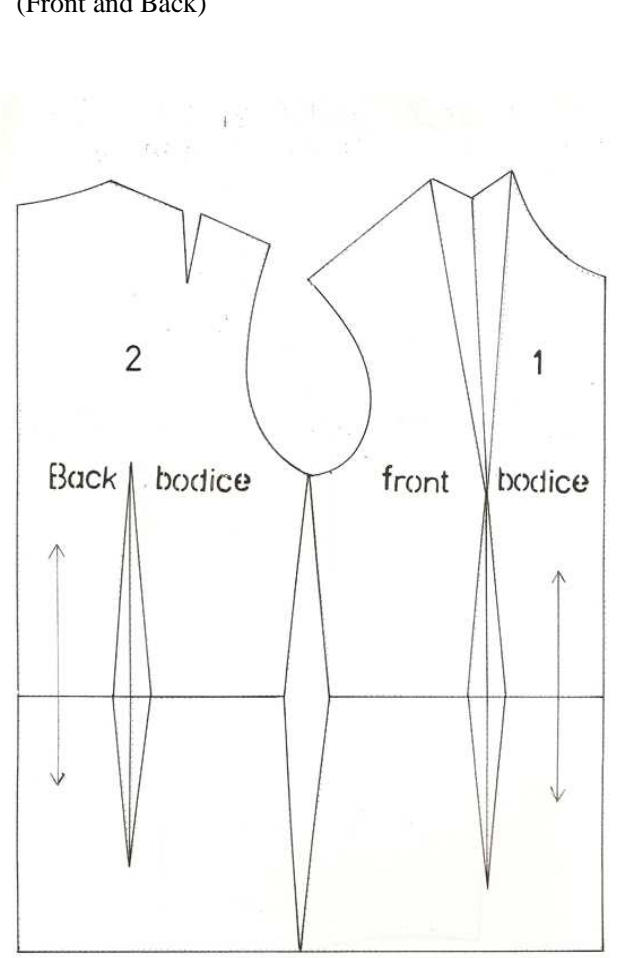

Figure 2: Drafted Sleeve Block

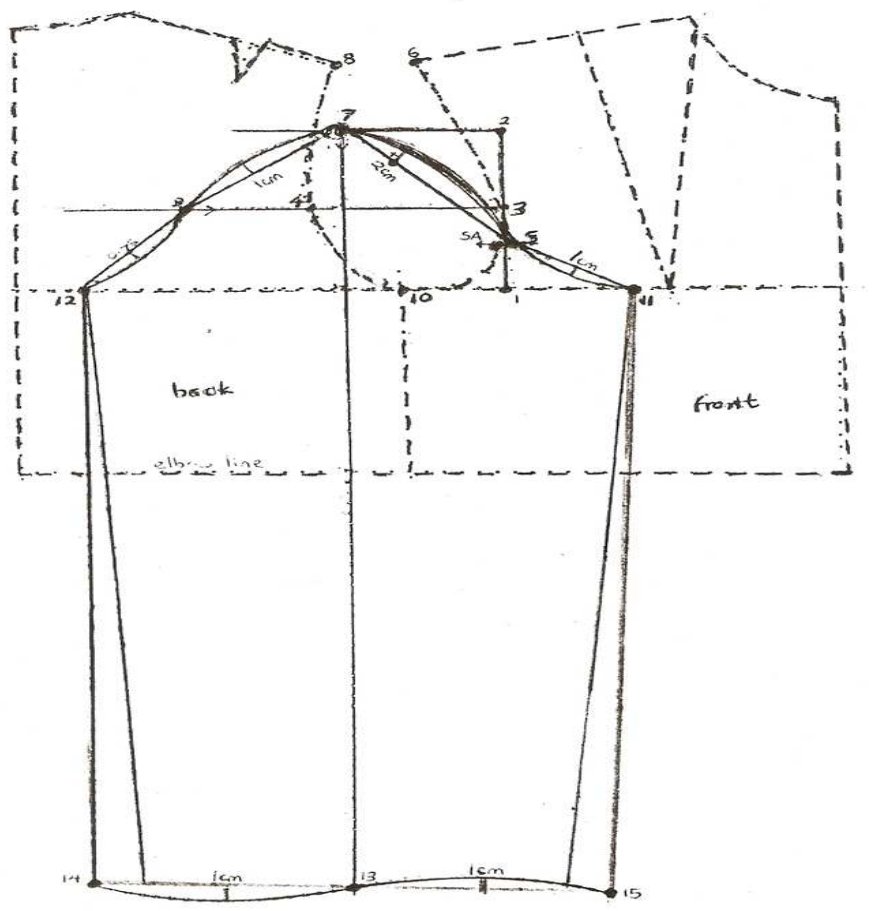

Figure 4: Developed Sleeve Block

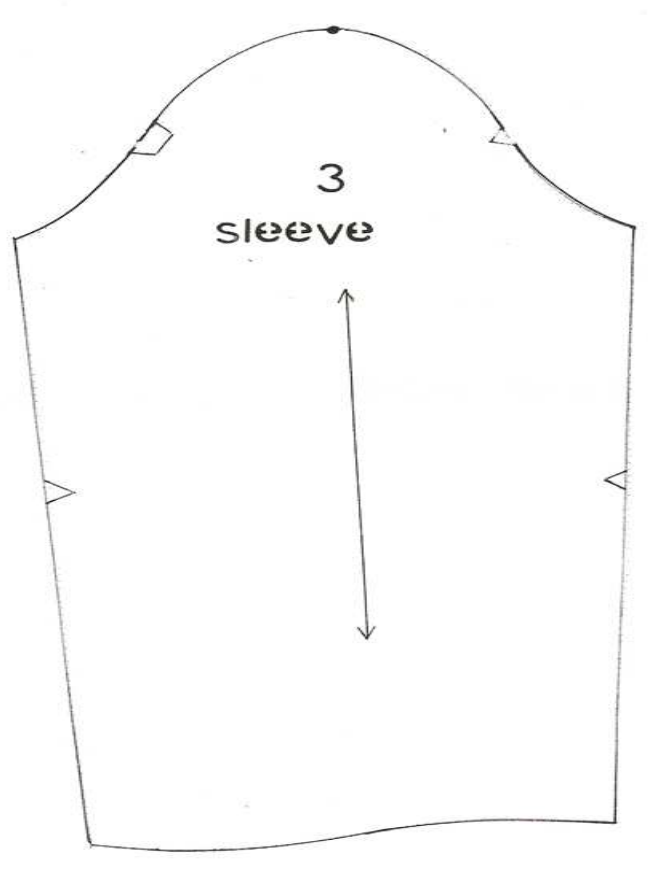


Iloeje, C.I. and Anyakoha, E.U.

In Table 2, the seamstresses rated the fit of the bodice for medium size satisfactory in all the 14 variables used for the assessment. For the students' rating, only one variable (item 5) 'waistline' out of the 14 variables for scoring the fit of the bodice for medium size fell short of the acceptable means for good fit which is $2.60-$ 3.35. The lecturers rated four variables out of 14 , poor fit. These include (item 3), 'bust ease', with a mean score of 3.40, (item 4) 'upper back' that has a mean score of 3.50 , (item 8 , 'bodice front waistline dart length', with a mean score of 3.40 and (item 13), 'sleeve length', which has a mean score of 3.40. The mean scores of the three sets of judges, that is, the grand mean fell within the range of $2.90-3.27$ which is indicative of good fit.

There were no significant differences in the mean ratings of the judges on the fit of the bodice for medium size on 12 out of 14 variables used for the assessment. Significant difference occurred in two items, 'front bodice waistline dart length' (item 8) and 'back bodice waistline dart length' (item 9). The null hypothesis of no significant difference was therefore rejected for these two variables.

Table 3 shows that the lecturers rated 12 variables out of 14 items used in the assessment of the fit of the blouse for large size, satisfactory. The two variables that fell short of satisfactory were (item 2), 'shoulder seam length', with a mean score of 2.50 and (item 8, 'front bodice waistline dart length,' with a mean score of 3.40. The mean scores of both the students and seamstresses were within the range of $2.70-3.10$ which is indicative of good fit.

The hypothesis testing shows no significant difference in the mean ratings of the judges on 13 out of 14 variables used for testing the fit of the bodice for large size. Thus the null hypothesis of no significant difference was rejected for 'shoulder seam length' only and accepted for the rest of the 13 variables used in testing the fit of the bodice for large size.

Table 2: Mean, F-ratio and DNMRT Results of the Judges on the Fit of the Bodice for Medium Size

\begin{tabular}{|c|c|c|c|c|c|c|c|}
\hline $\mathrm{S} / \mathrm{N}$ & Variables & $\overline{\bar{X}}_{1}$ & ${\overline{X_{2}}}_{2}$ & $\bar{X}_{3}$ & $\bar{X}_{4}$ & F-Cal & Sig. \\
\hline 1 & Neck line & 3.00 & 3.00 & 3.00 & 3.00 & - & - \\
\hline 2 & Shoulder seam length & 3.00 & 3.00 & 2.80 & 2.93 & 2.250 & .125 \\
\hline 3 & Bust ease & $3.40^{* *}$ & 3.20 & 3.20 & 3.27 & .643 & .534 \\
\hline 4 & Upper back & $3.50 * *$ & 3.30 & 3.00 & 3.27 & 1.988 & .156 \\
\hline 5 & Waistline & 3.30 & $3.40 * *$ & 3.10 & 3.27 & 1.167 & .327 \\
\hline 6 & Waistline placement (front) & 3.00 & 2.90 & 3.00 & 2.97 & 1.000 & .381 \\
\hline 7 & Waistline placement (back) & 3.00 & 2.90 & 3.00 & 2.97 & 1.000 & .381 \\
\hline 8 & Front bodice waistline dart length & $3.40_{\mathrm{a}} * *$ & $3.00_{\mathrm{b}}$ & $3.10_{\mathrm{ab}}$ & 3.17 & 3.545 & $.043^{*}$ \\
\hline 9 & Back bodice waistline dart length & $3.00_{\mathrm{b}}$ & $3.30_{\mathrm{a}}$ & $3.00_{\mathrm{b}}$ & 3.10 & 3.857 & $.034^{*}$ \\
\hline 10 & Armscye depth & 2.90 & 2.80 & 3.00 & 2.90 & 1.080 & .354 \\
\hline 11 & Ease at biceps & 3.10 & 3.20 & 3.20 & 3.17 & .220 & .804 \\
\hline 12 & Sleeve cap ease & 2.90 & 2.90 & 3.00 & 2.93 & .500 & .612 \\
\hline 13 & Sleeve length & $3.40 * *$ & 3.30 & 3.00 & 3.23 & 2.600 & .093 \\
\hline 14 & Armhole seam & 3.20 & 3.10 & 3.00 & 3.10 & 1.080 & .354 \\
\hline
\end{tabular}

$\bar{X}_{1}=$ mean ratings by lecturers, $\bar{X}_{2}=$ mean ratings by students, $\bar{X}_{3}=$ mean ratings

by seamstresses, $\bar{X}_{4}=$ grand mean, $*$ = significant, $\mathrm{P}=.05$, ** $=$ poor fit, a $=\mathrm{ab}$ (no

significant difference), $b=a b$ (no significant difference), $a \neq b$ (significant difference) 
Table 3: Mean, F-ratio and DNMRT Results of the Judges on the Fit of the Bodice for Large Size

\begin{tabular}{|c|c|c|c|c|c|c|c|}
\hline $\mathrm{S} / \mathrm{N}$ & Variables (Bodice) & $\bar{X}_{1}$ & $\bar{X}_{2}$ & $\bar{X}_{3}$ & $\bar{X}_{4}$ & $\mathrm{~F}$ & Sig. \\
\hline 1 & Neckline & 2.70 & 2.90 & 3.00 & 2.87 & 2.100 & .142 \\
\hline 2 & Shoulder seam length & $2.50_{\mathrm{b}} * *$ & $3.00_{\mathrm{a}}$ & $3.00_{\mathrm{a}}$ & 2.83 & 9.00 & $.001 *$ \\
\hline 3 & Bust Ease & 2.70 & 3.00 & 3.00 & 2.9 & 2.340 & .116 \\
\hline 4 & Upper Back & 2.90 & 2.90 & 2.90 & 2.9 & - & - \\
\hline 5 & Waistline & 3.10 & 2.90 & 2.90 & 2.97 & .336 & .717 \\
\hline 6 & Waistline placement (front) & 2.90 & 2.80 & 3.00 & 2.9 & 1.080 & .354 \\
\hline 7 & Waistline placement (back) & 3.00 & 3.00 & 3.00 & 3.00 & - & - \\
\hline 8 & Front Bodice WL dart length & $3.40 * *$ & 3.00 & 3.10 & 3.17 & 2.208 & .129 \\
\hline 9 & Back Bodice W/L dart length & 3.00 & 3.10 & 3.00 & 3.03 & 1.000 & .381 \\
\hline 10 & Armsyce depth & 2.60 & 2.80 & 2.70 & 2.70 & .443 & .647 \\
\hline 11 & Ease at biceps & 3.00 & 3.00 & 2.90 & 2.97 & 1.000 & .381 \\
\hline 12 & Sleeve cap ease & 2.70 & 2.70 & 3.00 & 2.80 & 1.929 & .165 \\
\hline 13 & Sleeve length & 3.00 & 3.00 & 3.00 & 3.00 & - & - \\
\hline 14 & Armhole seam & 2.70 & 3.00 & 2.90 & 2.87 & 2.100 & .142 \\
\hline
\end{tabular}

$\bar{X}_{1}=$ mean ratings by lecturers, $\bar{X}_{2}=$ mean ratings by students, $\bar{X}_{3}=$ mean ratings

by seamstresses, $\bar{X}_{4}=$ grand mean, * = significant, $\mathrm{P}=.05$, ** $=$ poor fit, a $=$ ab (no significant difference), $\mathrm{b}=\mathrm{ab}$ (no significant difference), $\mathrm{a} \neq \mathrm{b}$ (significant difference) $\mathrm{WL}=$ waistline

\section{DISCUSSION}

Blocks are basic necessities in the construction of well-fitted garments. In particular, they are quite valuable for large-scale production of garments. The mean ratings of the judges on the fit of the bodice for the three sizes - small, medium and large were all indicative of good fit for nearly all the variables used for the assessment. The judges were consistent in their ratings on the fit of the garments constructed from the blocks. The good fit obtained must have resulted from accurate body measurements taken, precision in the drafting and development of the blocks as well as good construction technique employed in assembling the pattern pieces. The findings of this study will adequately empower garment makers with a technology for large scale apparel production for the target group. Professional tailors and seamstresses trained in the use of commercial patterns should be able to use patterns developed from the blocks for mass production of garments for females in the nursing profession, armed forces and other professions requiring uniforms. This will create jobs for Nigerians and at the same time make the citizens self reliant in apparel production. The implementation of the results of the study would also help in the realization of some of the objectives of the medium term economic development package of the Federal Government of Nigeria - NEEDS, which includes, reducing poverty, creating wealth and generating employment.

\section{REFERENCES}

Aldrich, W. (2002). Metric Pattern Cutting. (Rev. $3^{\text {rd }}$ ed.). Oxford: Blackwell Scientific Publications.

Bray, N., \& Haggar, A. (1994). Dress Pattern Designing. (5th ed.). Oxford: Blackwell Scientific Publications.

Federal Government of Nigeria (2004). Unpublished Monograph on National Economic Empowerment and Development Strategy (NEEDS). Abuja Nigeria: National Planning Commission.

Frings, G.S. (1999). Fashion: From Concept to Consumer. Upper Saddle River, NJ: Prantice-Hall Inc.

Hollen, N. R., \& Kundel, C.J. (1993). Pattern Making by the Flat-Pattern Method. $\left(7^{\text {th }}\right.$ ed.). New York: Macmillan Publishing Company.

Iloeje C.I. (2007). Development and Testing of Block Patterns for Female Youths in Tertiary Institutions in Enugu State of 
Iloeje, C.I. and Anyakoha, E.U.

Nigeria. PhD Thesis, University of Nigeria, Nsukka.

Iloeje C.I., \& Anyakoha E.U. (2003). Establishment of Average Body Measurements and the Development of Block Patterns for Female Adolescents in Nigeria. Journal of Home Economics Research. 5 (1), 18 - 23.

Jarrow, J., \& Dickerson, K. (1996). Inside the Fashion Business. Upper Saddle River, NJ: Merrill/Prentice Hall.

Kaka, H.J. (1990). Comparative study of body dimensions of 13 and 16 year old Berom girls towards the development of basic paper patterns. Nigerian Journal of Technical Education. 7 (1), 55 - 66.

National Union of Textile, Garment and Tailoring Workers of Nigeria (NUTGTW). (2004). "Winners, Loosers as Government Forecloses Textile Ban." Policy Review. Guardian. April, 2004, p.44.

Nordas, H.K. (2003). The Global Textile and Clothing Industry, Post the Agreement on Textiles and Clothing. Retrieved August 7, 2005 from http://www.wto.org/english/res_e/booksp _eldiscussion_papers

Oyejide, A., Ogunkola, A., \& Bankole, A. (2005). Import Prohibition as a Trade Policy Instrument: The Nigerian Experience. Retrieved August 7, 2005 from http://www.wto.org/english/rese/casestudi es e/case 32 e.htm

Rose, M. (2000). Firms, Networks and Business Values: The British and American Cotton Industries since 1750. Cambridge, UK : Cambridge University Press. 